\title{
Analysis of Bistatic Scattering of Electromagnetic Waves by Melting Layer
}

\author{
Binay Kumar Jha \\ Department of Physics, P.N. Campus, Pokhara, Nepal \\ Email: nepalbkjha@yahoo.com
}

\begin{abstract}
In this communication bistatic scattering of electromagnetic waves by the melting layer of precipitation has been presented. The bistatic radar reflectivities have been formulated and can be computed at 1-100GHz by applying the Mie theory for raindropsize distributions at rain rates below $12.5 \mathrm{~mm} / \mathrm{h}$. It is very important to study the integrated interference effects all along the propagation path as well as of greatest interest for evaluating the impact of the melting layer effects on bistatic interference for communications.
\end{abstract}

Key words: Bistatic scattering, interference, hydrometeors, melting layer

\section{Introduction}

The bistatic scattering of electromagnetic waves by hydrometeors include not only the interference between terrestrial radio-relay stations, but also the interference between earth stations and satellites. This problem has been accepted and discussed by several authors (1-7). 10, 14, Kharadly et al [8] showed that melting layer where snowflakes melt and become raindrops can affect these interference problems. The bistatic transmission loss due to hydrometers in the melting layer may not be neglected because the bistatic radar reflectivity (the bistatic radar cross section per unit volume) is needed in the transmission loss evaluation [6] there are incentives for studying bistatic scattering of radio waves by the melting layer of precipitation. The bistactic radar reflectivity allows one to evaluate the interference caused by both copolarized and crosspolarized unwanted signals as well as the additional transmission loss due only to the bistatic scattering by the melting hydrometeors.

The monostatic radar measurements $[9,10]$ showed a special case of the bistatic scatter from the melting layer as experimental evidences. The radar bright band at centimeter wavelengths $[9,10]$ demonstrated that the radar backscatter from the melting layer is significantly larger than that from hydrometeors on both sides of the melting zone. The same has been experimentally shown for the forward scatter case [11] Russchenberg [9] demonstrated that at the top of the melting layer the vertical and horizontal reflectivities of snowflakes in the initial phase are equal. The differential reflectivity technique [12] has involved into a powerful remote sensing methodology. It was found [7] that the bistatic radar reflectivities computed by Mie- theory assuming spherical hydrometeors contain all necessary characteristics applied to the bistatic transmission loss computation. The established expectations for the bistatic effects within the melting layer. Although much previous work had been done in extending it to spheroids, the Mie theory could apply to the differential reflectivity and other polarization problem successfully.

Here in this article, we present bistatic radar reflectivities of the melting layer in the light of Mie theory.

\section{Mathematical Formulation}

The bistatic reflectivity $\gamma_{\mathrm{ij}}$ (the bistatic cross section per unit volume in $\mathrm{m}^{2} / \mathrm{m}^{3}$ is defined by $\gamma_{\mathrm{ij}}=\gamma_{\mathrm{ij}}(\mathrm{z})=$ $a_{\text {max }}$

$\sigma \int \sigma_{i j}\left(a_{2}\right)\left[Q+(1-Q)\left(a_{s 0}+k_{s} a\right)^{3} / a^{3}\right]^{03} N(a) d a$

In this equation, $\mathrm{z}$ is a depth below the top of the melting layer i.e, the $0^{\circ} \mathrm{C}$ isotherm, $a_{z}$ and $a$ the melting snow particle and resultant raindrop radii, respectively, and $\mathrm{a}_{\max }=0.325 \mathrm{~cm}$ is the max raindrop radius. Large raindrops may rarely be found at rain rates below $12.5 \mathrm{~mm} / \mathrm{h}$. Here, $\mathrm{a}_{\max }=0.325 \mathrm{~cm}$ used is the up limit of the integration concerning the drop-size distribution $\mathrm{N}$ (a)- moreover, Q is the ratio of melted mass to total mass of a melting snowflake and has been related to physical constants and meteorological parameters $[8] \mathrm{k}_{\mathrm{s}}=1.37$ and $\mathrm{a}_{\text {so }}$ $=0.005 \mathrm{~cm}$. In the particular, $\sigma_{\mathrm{ij}}\left(\mathrm{a}_{\mathrm{z}}\right)$ is the bistatic cross-section [8] of a single melting snow particle, $i$ 
and $\mathrm{j}$ denote the incident and received polarizations, respectively and the polarization refers to a plane determined by the z-axis and the incident or scattering direction. The bistatic scattering geometry is shown at Fig. 1.

The model describing the melting process was developed in [8]. It consists of the size distribution of melting snowflakes, the complex relative permittivity $\epsilon_{\mathrm{av}}$ of a melting snowflake, the thickness $Z_{m}$ of a melting layer and the density $\rho_{\mathrm{s}}$ of dry snowflakes on the top of the melting layer. Specifically, a relates a as

$$
a_{z}^{3}=a^{3}\left[Q+(1-Q) \frac{\rho_{w}}{\rho_{s}}\right]
$$

Where $\rho_{\mathrm{w}}=1 \mathrm{~g} / \mathrm{cm}^{3}$ is the density of water. The mass fraction $\mathrm{Q}=0$ corresponds to dry snowflakes. As a result, equation (2) becomes $\mathrm{a}_{2}^{3}$ $\rho_{\mathrm{s}}=\mathrm{a}^{3} \rho_{\mathrm{w}}$. This indicates the mass conservation. In the final phase of $Q=1$, equation (2) leads to $\mathrm{a}_{2}=\mathrm{a}$; snowflakes become raindrops.

Let $\mathrm{dn}$ be the melting snowflake number per unit volume at the melting snowflake radius interval of from $a_{2}$ to $a_{2}+d a_{2}$. In equation (1), dn has been expressed as

$$
\mathrm{dn}=\left[\mathrm{Q}+(1-\mathrm{Q})\left(\mathrm{a}_{\mathrm{so}}+\mathrm{k}_{\mathrm{s}} \mathrm{a}\right)^{3} / \mathrm{a}^{3}\right]^{\mathrm{V} / 3} \mathrm{~N}(\mathrm{a}) \mathrm{da} .
$$

Here, the density ratio of $\rho_{w} / \rho_{s}$ has been written as $\rho_{w} /$ $\rho_{\mathrm{s}}=\left(\mathrm{a}_{\mathrm{s}} \mathrm{o}+\mathrm{k}_{\mathrm{s}} \mathrm{a}\right)^{3} / \mathrm{a}^{3}$. Specifically, $\mathrm{z}_{\mathrm{m}}$ not only increase with a but also depends on other physical constant and meteorological parameters. The maximum thickness $\mathrm{H} \approx 1417 \mathrm{~m}$ is the value of $\mathrm{z}_{\mathrm{m}}$ at amax $=$ $0.325 \mathrm{~cm}$. In the later numerical result presentations, the ratio of $\mathrm{z} / \mathrm{H}$ will be employed where $\mathrm{z}$ takes value in the interval of $\mathrm{o} \leq \mathrm{z} \leq \mathrm{H}$. The $0^{\circ} \mathrm{C}$ isotherm indicated by 0 in fig. 1 correspond to $\mathrm{z} / \mathrm{H}=0$ or $\mathrm{Q}=0$. Specifically, $\gamma_{\mathrm{ij}}(\mathrm{z})$ can be computed for five raindrop-size distributions at rain rates below $12.5 \mathrm{~mm} / \mathrm{h}$. At the bottom of the melting layer, i.e., $\mathrm{z} / \mathrm{H}=1$, all snowflakes melt and become rain drops. As such, equation (1) becomes well known bistatic radar reflectivity for raindrops as expected.

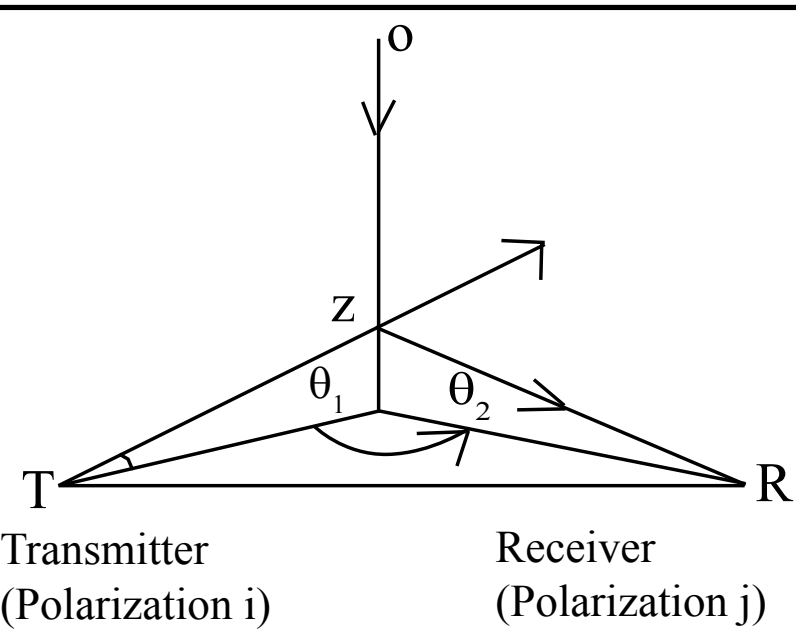

Fig 1. The bistatic scattering geometry for calculating bistatic radar reflectivity

In special case $\theta_{1}=\theta_{2}=90^{\circ}$ and $\phi=0^{\circ}$, the equivalent reflectivity factor $\mathrm{z}_{\mathrm{eq}}(\mathrm{z})$ [8] can be derived from equation (1). It has been shown [8] that results computed at 3-10 $\mathrm{Gh}_{\mathrm{z}}$ are adequate for describing the radar bright band. Further more, results computed at 35 and $94 \mathrm{GH}_{\mathrm{z}}$ indicate the fact that the radar bright band observed at centimeter wavelength can be absent at millimeter wavelengths [10]. In conclusion, $\mathrm{Z}_{\text {eq }}(\mathrm{z})$ computed applying the Mie theory agrees with radar observation of the melting layer at $3-94 \mathrm{GH}_{z}$.

\section{Numerical Results}

Numerical calculations can be performed at 1-100 $\mathrm{GHz}$ by applying Mie theory [13]. In table-1, the complex relative permittivity $\epsilon_{\mathrm{av}}$ at $35 \mathrm{GH}_{\mathrm{z}}$ as a function of Q for $\rho_{\mathrm{s}}=0.3485 \mathrm{~g} / \mathrm{cm}^{3}$ has been listed. In the initial phase of $Q=0, \epsilon_{a v}$ has the value of permittivity $\epsilon_{\mathrm{s}}$ dry snowflakes. These dry snowflakes consist of ice and air. Therefore, $\epsilon_{\mathrm{s}}$ depends on the volume fraction of ice and, hence, on $\rho_{\mathrm{s}}$. The density $\rho_{\mathrm{s}}$ has been related to the resultant raindrop radius a [8]. The initial density $\rho_{\mathrm{s}}=0.3485 \mathrm{~g} / \mathrm{cm}^{3}$ corresponds to the dry snowflakes that melt and become raindrops with $\mathrm{a}=0: 1 \mathrm{~cm}$. In the final phase of $\mathrm{Q}=1$, table- 1 shows $\epsilon_{a v}=\epsilon_{w}$, where $\epsilon_{w}$ is the $0^{\circ} \mathrm{C}$ water Complex relative permittivity [14] at $35 \mathrm{GH}_{z}$.

Also, $\gamma_{i j}(Z)$ can be computed for studying the interference between earth stations as well as that between earth stations and satellites [15]. These bistatic radar reflectivities cooperating with the 
The Himalayan Physics, Vol.1, No.1, May 2010

bistatic radar equation [16] would allow one to deal with the three kind interference problems including the melting layer effects for engineering purposes.

\section{Table 1}

The complex relative permittivity $\epsilon_{\mathrm{av}}$ of melting snowflakes at $35 \mathrm{GHz}$ for initial density $\rho_{\mathrm{s}}=0.3485 \mathrm{~g} / \mathrm{cm}^{3}$

\begin{tabular}{|c|c|c|}
\hline $\mathrm{Q}$ & $\operatorname{Re}\left\{\epsilon_{\mathrm{av}}\right\}$ & $\mathrm{I}_{\mathrm{m}}\left\{\epsilon_{\mathrm{as}}\right\}$ \\
\hline 0.0 & 1.670 & $9.418 \mathrm{E}-04$ \\
\hline 0.1 & 1.898 & $4.024 \mathrm{E}-01$ \\
\hline 0.2 & 2.167 & $8.822 \mathrm{E}-01$ \\
\hline 0.3 & 2.489 & 1.466 \\
\hline 0.4 & 2.882 & 2.190 \\
\hline 0.5 & 3.371 & 3.114 \\
\hline 0.6 & 3.999 & 4.332 \\
\hline 0.7 & 4.829 & 6.012 \\
\hline 0.8 & 5.977 & 8.473 \\
\hline 0.9 & 7.653 & 12.42 \\
\hline 1.0 & 10.25 & 19.75 \\
\hline
\end{tabular}

\section{Conclusions}

An analytical study on bistatic scattring of electromagnetic waves by the melting layer has been presented. The bistatic radar reflectivity has been formulated $(1-100 \mathrm{GHz})$ by applying the Mie theory for raindrop - size distributions at rain rates below $12.5 \mathrm{~mm} / \mathrm{n}$. It is very important to study the integrated interference effects all along the propagation path. The relative contribution of the melting layer's contribution to this integrated effect from the entire propagation path is of the greatest interest for evaluating the impact of the melting layer effects on bistatic interference.

\section{References:}

1. J. Awaka and T. Oguchi, "Bistatic radar reflectvities of Pruppacher and Pitter from raindrops at $34.8 \mathrm{Ghz}$ ", Radio Sci, Vol. 17, pp. 269-278, Jan/Feb 1982.

2. T. Oguchi, "Electromagnetic wave propagation and Scattering in rain and other hydrometors," Proc:IEEE, vol.71 pp.1029-1078 Sept.1983,

3. CCIR Rep. 569-4, The evaluation of propagation factors in interference problems between stations on the surface of the earth at frequencies above about $0.5 \mathrm{GH}_{\mathrm{Z}}{ }$, XVIIth Plenary Assembly, Dusseldodrof, Germany, May21June'1, pp.565-591.
4. J.D. Kavellopoulos and V.A. Houdzoumis, "A model for the prediction of differential rain attenuation on adjacent earth-space propagation paths", Radio Sci; vol.25, pp.853864 Sept/Oct.1990.

5. W.R. Stone, The Review of radio Science 1990-1992, New York: Oxford Univ. Press, 1993.

6. A.R. Holt, R. McGuinness, D.G. Charlton, P.T. Thompson and M.J. Mehler," The development of a model to estimate the bistatic transmission loss associated with inter system interference propagation" vol.41, pp.1422-1431, Oct 1993.

7. W. Zhang, "Bistatic scattering of Microwave and Millimeter wave by a melting layer of Precipitation," in Proc. 23rd Eur. Microwave Conf., Madrid, pp.165-167, Sept.1993.

8. W.Zhang, "Scattering of radio waves by a melting layer of precipitation in backward and forward directions", IEEE Trans. Antennas propagation; Vol. 42, pp. 347-356, Mar 1994.

9. H.W.J. Russchenberg and L.P. Ligthart; "Back scattering by and propagation through the melting layer of precipitation" ESTEC contract PO 122859. Final Rep. 1993.

10. M.Turai, T. Kozu and H. Kumagai, "A rain retrieval method examined using airborne radar measurements of tropical storms", in proc. $23^{\text {rd }}$ Eur. Microwave conf., Madrid, September 1993, pp. 483-485.

11. R.J. Doviak and C.M. weil,: static radar detection of the melting layer", 9, Appl. Meteorol., Vol. 11, pp-1012-1016, 1972.

12. T.A. Seliga and V.N. Bringi, "Potential use of radar differential reflectivity measurements at orthogonal polarization for measuring precipitation," J.Appl. Meteorol; Vol. 15, pp. 69-76. Jan 1976

13. C.F. Bohren and D.R. Huffman, Absorption and scattering of light by small particles. New York : Wiley, 1983.

14. P.S. Ray, "Broadband complex refractive indices of ice and water," Appl. opt, Vol II, no. 8, pp. 1836-1844 Aug. 1972

15. R.L. Olsen, D.V. Rogers, R.A. Hulays and M.M.Z. Kharadly, "interference due to hydrometeor scatter on satellite commucication links," Proc. IEEE, Vol. 81, pp. 914-922, June 1993.

16. F. Haidara and c.W. Bostian, "Rain side-scatter interference in the satellite links of the 1990's, IEEE Trans Antennas Propagation, Vol. 41, pp 493-498, April 1993.

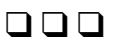

